\title{
Fuzzy PID Control Compensation System for Speed of VVVF Induction Motor Drive
}

\author{
Opas Ruksaboon and Chaiyapon Thongchaisuratkrul
}

\begin{abstract}
The objective of research was to present the closed loop speed controller of variable-voltage variable-frequency (VVVF) induction motor drive. The main issues regarding a Fuzzy PID controller were designed for controlling an induction motor. The proposed controller is composed the rule base with analysis two degree of freedom to fuzzy rule. The little fluctuation slope of rise time can be minimize with compensation Fuzzy and PID controllers. The study used LabVIEW program and adjustment of controller parameters were set consistently with the mathematic equation of the motor In this study, the $0.375 \mathrm{~kW}$ model of three phase induction motor was used in the simulation. The results showed that the Fuzzy PID controller can drive the induction motor system more effectively with good tracking and found robust is suitable for controlling the system.
\end{abstract}

Index Terms-Closed loop control, motor drive, fuzzy controller, PID controller.

\section{INTRODUCTION}

The induction motor is the electric motor type most used industry. The certain excellent features of the induction motor such as for the user this low cost and high reliability, good efficiency and low maintenance. The induction motors are asynchronous induction machines whose speed depends upon applied frequency, pole pair number, and load torque. This market need and growing at a healthy rate as users of operating motors at variable speeds [1].

The core of algorithm traditional control for induction motor drives were PI/PID control. That the simple structure and stable performance. But it is difficult to meet the high precision and fast response [2]. The Fuzzy Logic Control novel design applied for the speed of an induction motor [1], [3], [4]-[6].The fuzzy two-degree of freedom to obtain good tracking and regulating response [7]. An advantage of traditional controlled that can be easily modified into the conventional controller structure by adding a compensator [8], [9]. In addition, that the two-layered control structure is robust to variations, as well as the steady-state gain of the plant [10]. Unfortunately, in the real control application, a global model is very difficult to build, and even when a model is available, complex conditions are obtained.

The nonlinear system can be controlled if the dynamic

Manuscript received January 12; 2013; revised April 10, 2013.

Opas Ruksaboon is with the Department of Education Technology, Rajamangala University of Technology Isan, Khonkaen Campus, Thailand (e-mail: op_asr@ hotmail.com).

Chaiyapon Thongchaisuratkrul is with the Department of Teacher Training in Electrical Engineering, King's Mongkut University of Technology North Bangkok, Thailand (e-mail: srp@kmutnb.ac.th). model was established [11].Induction motor is a complex system, the control techniques such as PI, PID or Fuzzy controllers with auto-tuning function can be applied for driving [12], [13]. The compensation control system minimized torque ripple, reaches the reference speed rapidly and without overshoot [11], [14].The remainder of this paper is the further verification concept of high application in system drive. To find the Fuzzy PID control compensation performance of this system, the three phase induction motor with variable voltage-variable frequency technique (VVVF) is implemented. The computer control experimental was setup two-degree of freedom are chosen for rule base to compensating signal is added to PID by using LabVIEW. The simulation and real time control results are illustrated and compared.

\section{INDUCTION MOTOR DRIVE}

\section{A. Variable-Voltage Variable-Frequency (VVVF) Induction Motor Drive}

Some problem in the operation of induction motor this open-loop control are the following: the speed cannot be controlled precisely, the slip speed cannot be maintained [12]. These problems are to an extent overcome by having outer speed loop in the induction motor drive. The actual rotor speed $\left(V_{t g}\right)$ is compare with its command value $\left(V^{*}\right)$ and the error is processed a controller usually a PI/PID. The slip-speed command is added to electrical rotor speed to obtain the stator frequency command. Thereafter, the stator frequency command is processed as in driven unit. The constant of proportionality between the dc load voltage and the stator frequency. The closed-loop variable-voltage variable-frequency (VVVF) shown in Fig 1. The induction motor drive system, limits on the slip speed, offset voltage and reference speed are adjustable variables. The speed controlled with the inverter-driven motor apart from variable frequency. Thus, the speed can be derived as follows [12]:

$$
\begin{gathered}
E_{l}=4.4 K_{w l} \phi_{m} f_{s} T_{l} \\
V_{p h} \cong E_{l} \\
\phi_{m} \cong \frac{V_{p h}}{K_{b} f_{s}} f_{s} T_{l} \\
K_{v f}
\end{gathered}
$$

$K_{b}$ is constant value 


$$
\phi_{m} \propto \frac{V_{p h}}{f_{s}} \propto K_{v f}
$$

$K_{v f}$ is the ratio between $V_{p h}$ and $f_{s}$

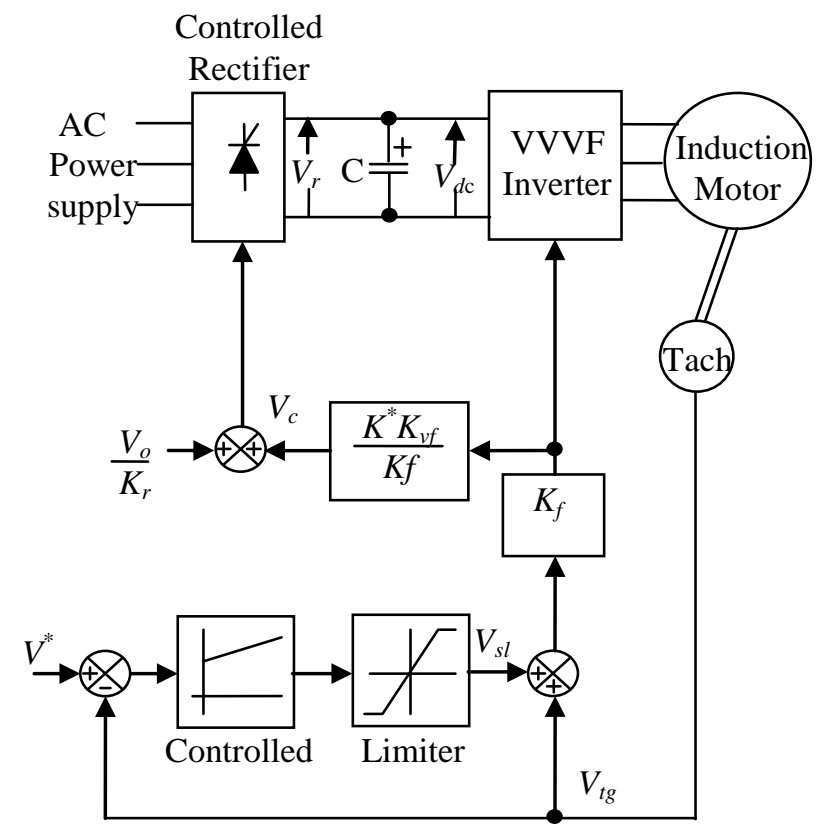

Fig 1. Overall block diagram of the VVVF controlled induction motor drive. [15]:

The external drive with input voltage $V^{*}$ is used as follows

$$
-V_{c m}<V^{*}<+V_{c m} \quad V
$$

$V_{c m}$ is the maximum control voltage $( \pm 5$ or $\pm 10 V)$

$V^{*}$ is the command speed of the motor

The proportionality constant is defined as

$$
K^{*}=\frac{V^{*}}{\omega_{r}^{*}}=\frac{V_{c m}}{\max \left\{\omega_{r}^{*}\right\}} \operatorname{volt} /(\mathrm{rad} / \mathrm{sec})
$$

The gain of tachogenerator is defined as

$$
\begin{gathered}
K_{t g}=\frac{V_{c m}}{\omega_{m}}=\frac{V_{c m}}{\omega_{r} /(P / 2)}=\frac{P}{2} \cdot K^{*} \\
K_{f}=\frac{1}{2 \pi K^{*}} \quad \mathrm{~Hz} / \text { Volt }
\end{gathered}
$$

$K_{f}$ is the gain of the frequency transfer.

$\omega_{r}^{*}$ is the commanded electric rotor speed

$\omega_{r}$ is the electric rotor speed

Stator frequency are written

$$
\begin{aligned}
f_{s} & =K_{f}\left(K^{*} \omega_{s l}+\frac{P}{2} \cdot K^{*} \omega_{m}\right) \\
& =K_{f} K^{*}\left(\omega_{r}+\omega_{s l}\right) \quad \mathrm{Hz}
\end{aligned}
$$

$\omega_{s l}$ is the electric rotor slip-speed

The output of rectifier is given in terms as

$$
\begin{aligned}
& V_{c}=\frac{2.22}{K_{r}}\left(V_{o}+K_{v f} f_{s}\right) \\
& V_{r}=2.22 K_{f}\left\{V_{o}+K_{f} K^{*} K_{v f}\left(\omega_{r}+\omega_{s l}\right)\right\}
\end{aligned}
$$

The slip speed and the offset voltage are generalized as follows:

$$
\begin{gathered}
V_{o}=I_{s r} R_{s} \\
\omega_{s l}=f_{n}\left\{V^{*}-V_{t g}\right\} \\
=f_{n}\left\{V^{*}-\omega_{m} K_{t g}\right\} \\
=f_{n}\left\{K^{*} \omega_{r}^{*}-K^{*} \omega_{r}\right\}
\end{gathered}
$$

$I_{s r}$ is the rate stator current

$f_{n}$ is the speed controller function

The synchronous speed is given in terms as

$$
\omega_{s}=2 \pi f_{s}=2 \pi K_{f} K^{*}\left(\omega_{f}+\omega_{s l}\right)
$$

\section{B. Dynamic Modeling of Induction Motor}

The model of three-phase induction motor can be described as D-Q equivalent circuit [5], [6], [11]. Thus, the vector can be derived as follows:

$$
S=S_{q}-j S_{d}
$$

In other words, $S_{q}=\operatorname{Re}(S)$ and $S_{d}=-\operatorname{Im}(s)$

The dynamic equation of an induction motors can be used as a standard form of difference equation. Thus, we have

$$
p X=A X+B U
$$

The matrix quantities equation is given by

$$
\left[\begin{array}{c}
V_{a s} \\
V_{d s} \\
0 \\
0
\end{array}\right]=\left[\begin{array}{cccc}
R_{s}+L_{s} p & \omega_{e} L_{s} & L_{m} p & \omega_{e} L_{m} \\
-\omega_{e} L_{s} & R_{s}+L_{s} p & -\omega_{e} L_{m} & L_{m} p \\
L_{m} p & \omega_{r} L_{s} & R_{r}+L_{r} p & \omega_{r} L_{r} \\
-\omega_{e} L_{m} & L_{m} p & -\omega_{r} L_{r} & R_{r}+L_{r} p
\end{array}\right]\left[\begin{array}{c}
I_{q s} \\
I_{d s} \\
I_{q r} \\
I_{d r}
\end{array}\right]
$$

$\mathrm{X}=\left[\begin{array}{l}I_{q s} \\ I_{d s} \\ I_{q r} \\ I_{d r}\end{array}\right], \mathrm{U}=\left[\begin{array}{c}V_{q s} \\ V_{d s} \\ 0 \\ 0\end{array}\right], \mathrm{B}=1 / \Delta\left[\begin{array}{cccc}L_{r} & 0 & -L_{m} & 0 \\ 0 & L_{r} & 0 & -L_{m} \\ -L_{m} & 0 & L_{s} & 0 \\ 0 & -L_{m} & 0 & L_{s}\end{array}\right]$

and $\mathrm{A}=1 / \Delta$

$\left[\begin{array}{cccc}R_{s} L_{r} & \omega_{e} L_{s} L_{r}-\omega_{r} L_{m}{ }^{2} & -R_{r} L_{m} & \omega_{o} L_{m} L_{r} \\ \omega_{r} L_{m}{ }^{2}-\omega_{e} L_{s} L_{r} & R_{2} L_{r} & -\omega_{s} L_{r} L_{m} & -R_{r} L_{m} \\ -R_{s} L_{m} & -\omega_{o} L_{s} L_{m} & R_{r} L_{s} & \omega_{r} L_{s} L_{r}-\omega_{e} L_{m}{ }^{2} \\ \omega_{o} L_{s} L_{m} & -R_{s} L_{m} & -\omega_{e} L_{m}{ }^{2}-\omega_{r} L_{s} L_{r} & R_{r} L_{s}\end{array}\right]$

Then, we have $\Delta=L_{s} L_{r}-L_{m}{ }^{2}, \omega_{o}=p \theta_{0}$

The stator and the rotor voltage equations are given by

$$
\begin{gathered}
V_{q s}=R_{s} I_{q s}+p \lambda_{q s}+\omega_{s} \lambda_{d s} \\
V_{d s}=R_{s} I_{d s}+p \lambda_{d s}+\omega_{s} \lambda_{q s} \\
0=R_{r} I_{q r}+p \lambda_{q r}+\omega_{r} \lambda_{d r} \\
0=R_{r} I_{d r}+p \lambda_{q r}+\omega_{r} \lambda_{q r}
\end{gathered}
$$

The flux linkage equations are as follows:

$$
\begin{aligned}
& \lambda_{q s}=L_{s} I_{q s}+L_{m} I_{q r} \\
& \lambda_{d s}=L_{s} I_{d s}+L_{m} I_{d r} \\
& \lambda_{q r}=L_{m} I_{q s}+L_{r} I_{q r} \\
& \lambda_{d r}=L_{m} I_{d s}+L_{r} I_{d r}
\end{aligned}
$$

The torque equation is defined as

$$
T_{o}=\frac{3}{4} P\left(\frac{L_{m}}{L_{r}}\right)\left(\lambda_{d r} I_{q s}-\lambda_{q r} I_{d s}\right)
$$


The block diagram of induction motor dynamics is shown in Fig 2. [5], [6].

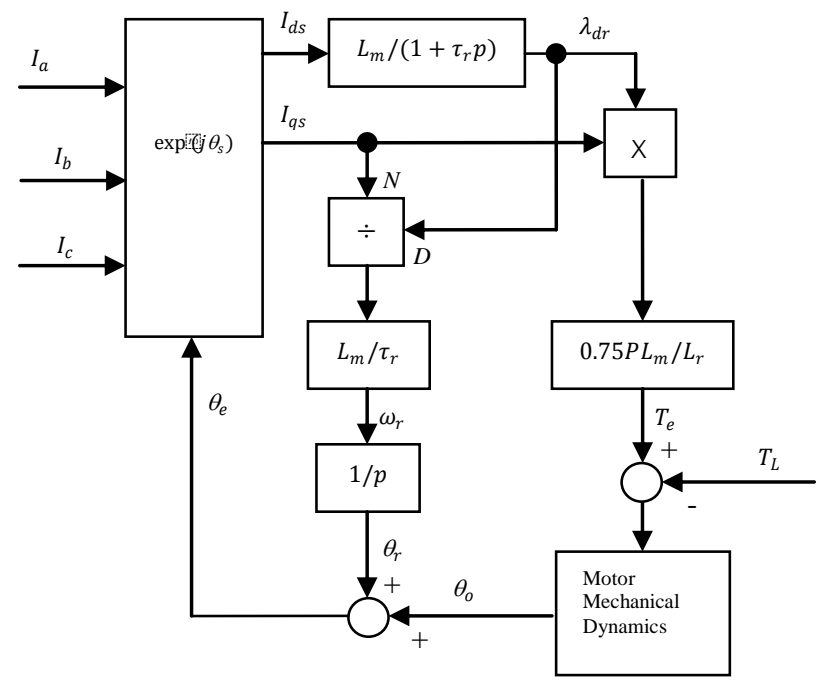

Fig. 2. Block diagram of induction motor dynamics.

The three phase induction motor's parameters are shown in Table I.

TABLE I: THE THREE PHASE INDUCTION MOTOR's PARAMETERS MODEL

\begin{tabular}{|l|l|}
\hline Parameter & Value \\
\hline Phase & 3 \\
\hline$V_{l l}:$ Line Voltage & $380 \mathrm{~V}$ \\
\hline$P:$ Number of pole & 4 \\
\hline Power & $0.375 \mathrm{KW}$ \\
\hline$f:$ Frequency & $50 \mathrm{~Hz}$ \\
\hline$R_{s}:$ Stator resistance & $0.005 p . u$. \\
\hline$R_{r}:$ Rotor resistance & $0.005 p . u$. \\
\hline$X_{l s}:$ Stator magnetizing leakage & $0.028 p . u$. \\
\hline$X_{l r}:$ Rotor magnetizing leakage & $0.025 p . u$. \\
\hline$X_{m}:$ Magnetizing resistance & $1.11 p . u$. \\
\hline$J:$ Inertia & $0.01 p . u$. \\
\hline
\end{tabular}

\section{CONTROLLER}

\section{A. PID Controller}

The classical PID control system (proportional-integral -Derivative control) is the methodology to relate system performance - error attenuation as a function of time [10]. The error (e) was compared $V^{*}$ command and $V_{t g}$ actual. Tuning the three parameters $K p, K i, K d$ in the controller were provide control design. The output terms are summed defining $u(k)$ the final form of the PID algorithm is given by:

$$
u(k)=k_{p} e(k)+k_{p} k_{i} \int_{0}^{t} e(t) d t+k_{p} k_{d} \frac{d e(t)}{d t}
$$

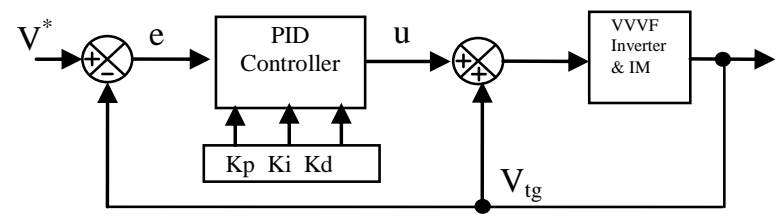

Fig. 3. Block diagram of a PID controller.

There are two ways of tuning:
Ziegler Nichols method is the type of controller turning base on the trial-and-error. In the process that calculated from start oscillating ultimate gain $K_{u}$, ultimate time period of oscillation $P_{u}$ are use to find the tuning constants for the Table II.

TABLE II: CONTROLLER PARAMETERS FOR ZIEGLER NICHOLS METHOD

\begin{tabular}{|l|l|l|l|}
\hline Controller & $K_{p}$ & $T_{i}$ & $T_{d}$ \\
\hline $\mathrm{P}$ & $0.5 K_{u}$ & $\infty$ & 0 \\
\hline $\mathrm{PI}$ & $0.45 K_{u}$ & $P_{u} / 1.2$ & 0 \\
\hline $\mathrm{PID}$ & $0.6 K_{u}$ & $P_{u} / 2$ & $\mathrm{P}_{u} / 8$ \\
\hline
\end{tabular}

Process reaction curve is the variables being measured of a system (open loop), in the process that calculated from the dead time $\left(\tau_{\text {dead }}\right)$, the time response to change $(\tau)$, the ultimate value at steady $\operatorname{state}\left(M_{u}\right)$ and the step change disturbance $x_{o}$.

$$
K_{o}=\frac{x_{o}}{M_{u}} \frac{\tau}{\tau_{\text {dead }}}
$$

$K_{o}$ and $\tau_{\text {dead }}$ were used to find the tuning constants for the Table III

TABLE III: CONTROLLER PARAMETERS FOR PROCESS REACTION CURVE
\begin{tabular}{|l|l|l|l|}
\hline Controller & $K_{o}$ & $T_{i}$ & $T_{d}$ \\
\hline $\mathrm{P}$ & $\mathrm{K}_{\mathrm{o}}$ & $\infty$ & 0 \\
\hline $\mathrm{PI}$ & $0.9 \mathrm{~K}_{\mathrm{o}}$ & $3.3 \tau_{\text {dead }}$ & 0 \\
\hline PID & $1.2 \mathrm{~K}_{\mathrm{o}}$ & $2 \tau_{\text {dead }}$ & $0.5 \tau_{\text {dead }}$ \\
\hline
\end{tabular}

The both turning methods, Hence in this paper decided to use Ziegler Nichols method. However, PID method is not robust, cannot accurately control. Among the successful application of this theory has been devoted to develop PID controller [10], [15].

\section{B. Fuzzy Logic Controller}

D. D. Neema, R. N. Patel, A. S. Thoke, represented the fuzzy set theory and application of FLC in IM [3]. Fuzzy logic controller (FLC) has found robust is suitable for controlling the system. The fuzzy theory is better performance than that a PID controller [2], [5], [6], [15]. Fig 4. shows the structure of a Fuzzy logic controller.

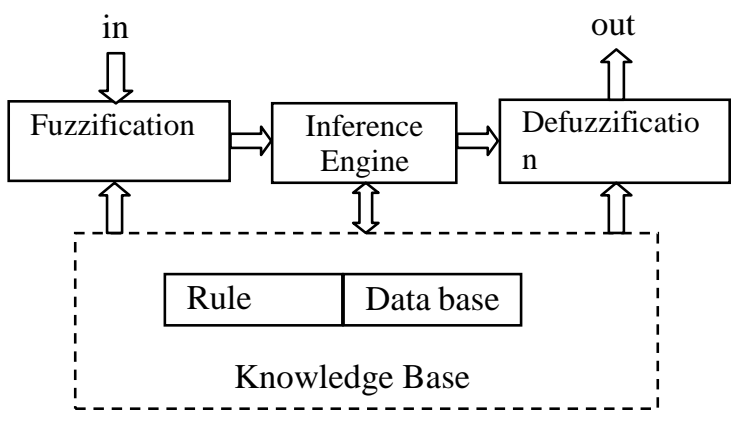

Fig. 4. Structure of a fuzzy logic controller.

The structure of fuzzy logic controller in general contains four main parts which are:
1) Fuzzification
2) Knowledge Base
3) Inference Engine
4) Defuzzification

The input variables go through the fuzzification interface that inform to linguistic variables. The rule base holding the 
decision-making logic used to infer the fuzzy output, a defuzzification converts the fuzzy output into a signal output.

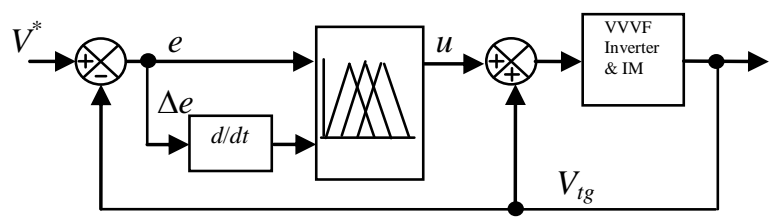

Fig. 5. Block diagram of a Fuzzy logic controller.

Fig. 5 shows the block diagram of a Fuzzy logic controller. The two variable input are the error of speed $(e)$ and the change in error of speed $(\Delta e)$. The output $(u)$ is voltage signal to control the amplifier and VVVF Inverter.

\section{Dynamic Signal}

Tracking and regulating that importance proposes to methodology design of system [7]. The speed error tuning to fasted by using the fuzzy controlled [5], [6], [9]. The two degrees of freedom that was to check the error and assisted $e$, $\Delta e$ input of Fuzzy Logic Controller (FCL). Fig. 6. shows the compared of the command, reference and dynamics signal.

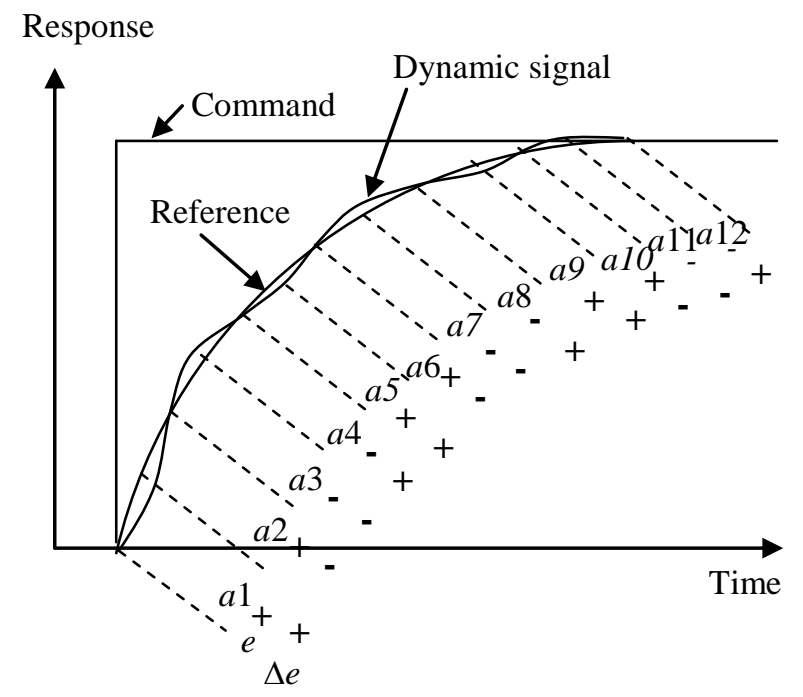

Fig. 6. Dynamics signal analysis: step command.

Our aim is to eliminate the steady state error and improve the performance of the output response for control system. The purposed controller we define the error $e(k)$ and change error $\Delta e(k)$ as follows [9], [15]:

$$
\begin{aligned}
& e(k)=V^{*}(k)-V_{t g}(k) \\
& \Delta e(k)=e(k)-e(k-1)
\end{aligned}
$$

$a 1, a 5, a 9: e=+$ and $\Delta e=+$, the error is positive and error increased

a2, a6, a10: $e=+$ and $\Delta e=-$, the error is positive and error decreased

a3, a7, a11: $e=-$ and $\Delta e=-$, the error is negative and error increased

$a 4, a 8, a 12: e=-$ and $\Delta e=+$, the error is negative and error decreased, the error is positive and error increased

\section{Design of Fuzzy Tuning Speed Controller}

The error $(e)$, change in error $(\Delta e)$ and output variable $(u)$ are represented as linguistic values as follows:

1) Fuzzy number

- Positive Big: PB Positive Medium: PM

- Positive Small: MS Zero: ZE

- Negative Small: NS Negative Medium: NM

- Negative Big: NB

\section{2) Membership function}

In this paper, the triangular-shaped functions were selected. The fuzzy number and membership function is shown in Fig. 7.
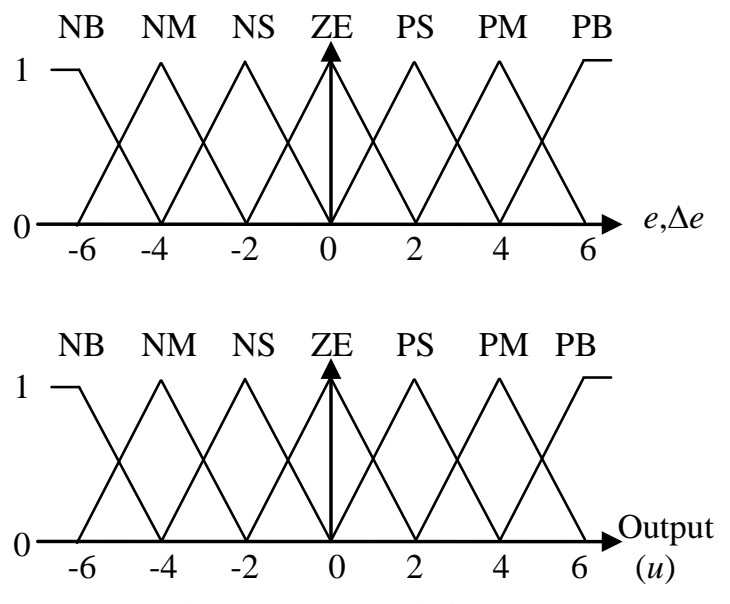

Fig. 7. The membership functions

\section{3) Quantization levels}

Fuzzy sets of a FLC shows the corresponding rule table for the speed control. There are $7 \times 7=49$ possible rules in the matrix, for example as follows:

If $e$ negative small (NS) and $\Delta e$ is positive small (PS) then output $(u)$ is zero $(Z E)$.

\begin{tabular}{|c|c|c|c|c|c|c|c|}
\hline $\begin{array}{c}\Delta e \\
e\end{array}$ & NB & NM & NS & ZE & PS & PM & PB \\
\hline NB & NB & NB & NB & NB & NM & NS & ZE \\
\hline NM & NB & NB & NB & NM & NS & ZE & PS \\
\hline NS & NB & NB & NM & NS & ZE & PS & PM \\
\hline ZE & NB & NM & NS & ZE & PS & PM & PB \\
\hline PS & NM & NS & ZE & PS & PM & PB & PB \\
\hline PM & NS & ZE & PS & PM & PB & PB & PB \\
\hline PB & ZE & PS & PM & PB & PB & PB & PB \\
\hline
\end{tabular}

The fuzzy inference process to calculated fuzzy output. The Mamdani's method that found suitable for DC machine or Induction machine [7]. The Mamdani's method was convert fuzzy output into the crisp value of the output variable. This method, the centre of area (COA) de-fuzzification method is generally used. The crisp value of the output variable torque is applied to the VVVF inverter. The VVVF inverter controlled the magnitude and frequency of the $V / f$ to desired speed of the motor.

\section{E. Fuzzy PID Compensation System}

The PID controllers are widely, exhibit poor performance when applied to nonlinearities [9]. However, the PID controllers are minimized the steady state error system. The closed loop PID controller can be used controls the speed of DC motor [10]. A variable gain PI controller that designed to replace the classical PI the motor reaches the reference speed 
rapidly and without overshoot [16]. The constant flux of three phase induction motor drives using fuzzy logic controller that has been achieved in rise time and steady state of speed controlled [3], [5], [6]. The robust, tracking and regulating of induction motor drive that analysis by compensated method [9], [17]. Hence, Fuzzy PID compensation control can improve of the performance single loop control. The Fuzzy PID compensation structures system is shown in the Fig. 8.

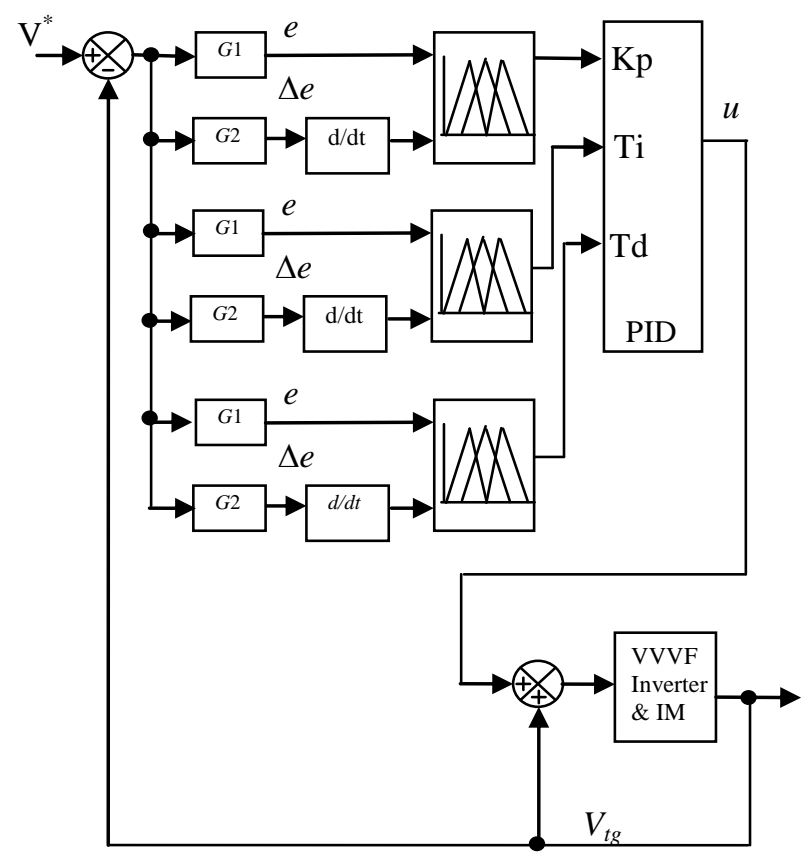

Fig. 8. Block diagram of the Fuzzy PID control system.

\section{F. Simulation the Speed Control System}

The system is modeled and implemented via LabVIEW program is shown in Fig 9. For the turning in this paper, we set PID gains with Ziegler Nichols and trial-error method. The variable quantities of $K p, T i, T d$ are derived by fuzzy logic controller.

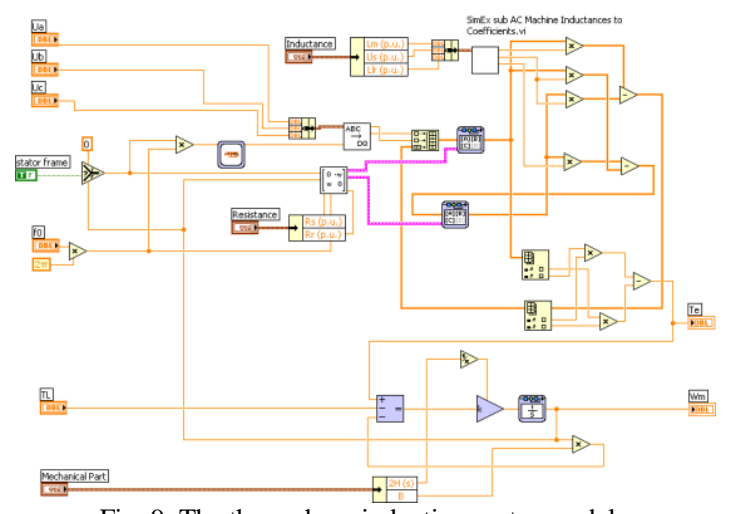

Fig. 9. The three phase induction motor model.

Experiment 1. The PI VVVF controller set references speed $=0.6 \mathrm{pu}, K p=0.045, K i=0.009$ for the no load 0.375 $k W, 3$-phase induction motor started. And take load $0.5 p_{u}$. at 3 second of time.

Experiment 2. The Fuzzy PID compensation VVVF drive set values are references speed $=0.6 p u$., $G 1=3.8, G 2=$ $0.345, K p=20, T i=0.008$ and $T d=0.001$, for the no load $0.375 \mathrm{~kW}, 3$-phase induction motor started. And take load 0.5 $\mathrm{pu}$. at 3 second of time.
Experiment 3. The Fuzzy PID compensation VVVF drive set values are references speed $=0.5 \mathrm{pu}$. , G1 $=3.8, G 2=$ $0.345, K p=20, T i=0.008$ and $T d=0.001$, for the no load $0.375 \mathrm{~kW}, 3$-phase induction motor started. And take load 0.5 $p u$. at 3 second of time.

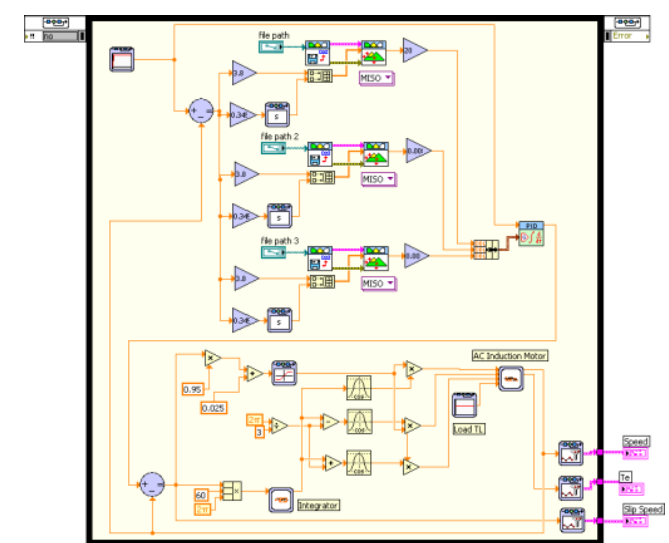

Fig. 10. The Volt/Hz controlled induction motor drive usually is a Fuzzy PID compensation controller.
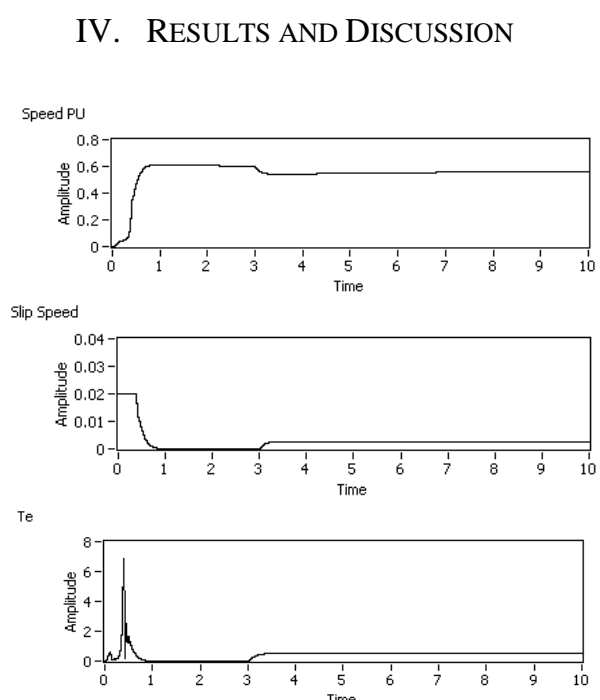

Fig. 11. Result of induction motor PI VVVF controller drive. The simulation of speed, slip speed and Te with references speed $=0.6$ pu., $\mathrm{Kp}=0.045, \mathrm{Ki}=$ 0.009 , load $0.5 \mathrm{pu}$. at $3 \mathrm{sec}$.

The speed responses with the step speed references input are implemented by LabVIEW program. The parameters from table I. are used and the references speed is referred to $0.6 \mathrm{pu}$. and $0.5 \mathrm{pu}$. The first simulation is setup for the no load $0.375 \mathrm{~kW} \mathrm{3-}$ phase induction motor and take load $0.5 \mathrm{pu}$. at 3 second of time. The simulation model in LabVIEW is shown in Fig. 9 and Fig 10. The results of PI VVVF controller drive obtained by $K p=0.045, K i=0.009$ is shown in Fig. 11 . Membership function of error and change in error are the same. The inputs of fuzzy logic controller are the error and change in error. The variable quantities of PID parameters are derived by fuzzy reasoning, and corresponding values for PID control parameter are tuned (use of the Ziegler-Nichols and trial-error method) until the output follows the set point adequately. The proportional parameter $K p$ obtained between 20 and 25. The integration parameter $K i$ obtained between 0.008 and 0.006 . The differential parameter $K d$ obtained between 0.001 and 0.0015 . The results of PI VVVF control and Fuzzy PID compensation VVVF control are compared 
and showed in Fig. 11-Fig. 13.
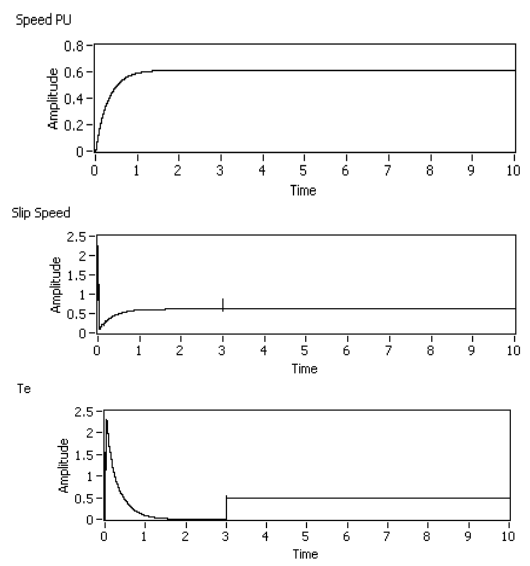

Fig. 12. Result of induction motor Fuzzy PID compensation VVVF drive. The simulation of speed, Te and Slip speed with references speed $=0.6 \mathrm{pu}$. $K p=20, T i=0.008, T d=0.001$, load 0.5 pu. at $3 \mathrm{sec}$.

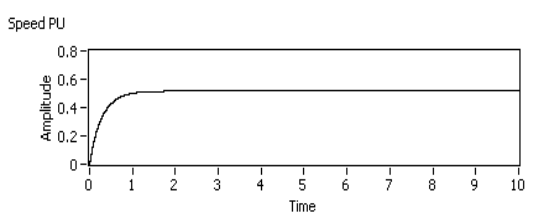

Slip Speed
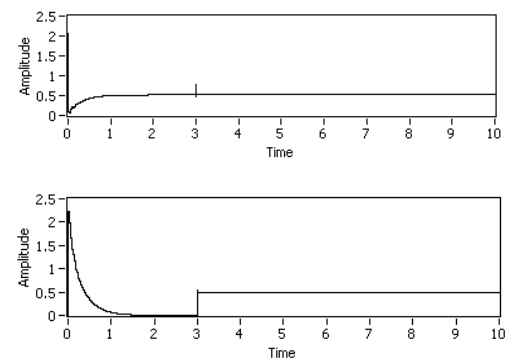

Fig. 13. Result of induction motor Fuzzy PID compensation VVVF drive. The simulation of speed, Te and Slip speed with references speed $=0.5 \mathrm{pu}$. $K p=20, T i=0.008, T d=0.001$, load $0.5 p u$. at $3 \mathrm{sec}$.

The speed response of PI VVVF controller have the little fluctuation slope of rise time. an approximately 0.9 second for rise time. The slip speed 0.02 at 0 to 0.6 second and fall to 0 at 0.9 second. The maximum value of Te an approximately $7 \mathrm{Nm}$, and fluctuation during 0 to 0.9 second. When take load $0.5 \mathrm{pu}$. at 3 second of time the speed response have fall, and little of fluctuation.

The speed response of Fuzzy PID compensation VVVF controller have smooth slope of rise time, an approximately 0.9 second for rise time. The slip speed has little spike when start and take load at 3 second. The maximum value of Te an approximately $2 \mathrm{Nm}$, and smooth curve during 0 to 1.2 second. The Te has rapidly response and were set when take load. The numerical results are presented when take load 0.5 $p u$. at 3 second of time the speed response is robust to variations in load.

\section{CONCLUSION}

The Fuzzy PID compensation system has been developed for speed control of induction motor for simulation $0.375 \mathrm{~kW}$ 3 - phase induction motor. The performance of Fuzzy PID compensation VVVF controller and PI VVVF controller in terms of setting time, speed and torque are shown for variation in reference speed and load torque, which simulation results the improved regulation with smaller value of setting time. In all simulation test results of speed and torque response are achieved with the Fuzzy PID compensation system. The Fuzzy PID compensation VVVF strategy can drive an induction motor system more effectively. The heuristic knowledge is improved into the design of rule base and heave compensation system, that the resulting in a nonlinear control performance over linear conventional PI controller. The new and improved control technique for driven has good tracking and found robust is suitable for controlling the system.

\section{REFERENCES}

[1] N. Mohan, Electric Drives and Integrative Approach, MNPERE, 2003

[2] H. Zhu et al. (August 2011). Intelligent and applications. MECS [Online]. pp. 28-33. Available: http://www.mecs-press.org/

[3] D. D. Neema, R. N. Patel, and A. S. Thoke, "Speed control of induction motor using fuzzy rule base," International Journal of Computer Applications, vol. 33, no. 5, November 2011.

[4] H. B. Bostan, A. Y. V. Abad, and T. Asghar, "Using fuzzy controller in induction motor speed control with constant flux," PWASET, vol. 5, 2005.

[5] O. Ruksaboon and S. Thongchai. "Simulation of 3-phase induction motor control system using fuzzy-vector of variable frequency," in Proc. the $2^{\text {th }}$ RIIT 2009 International Conf., 2009.

[6] O. Ruksaboon and C. Thongchaisuratkrul. "Constant flux of three phase induction motor drives using fuzzy logic controller," in Proc. the $5^{\text {th }}$ Conf. of TRS Conf. on Robotics and Industrial Technology, 2011.

[7] C. M. Liaw and S. Y. Cheng, "Fuzzy two degrees of freedom speed controller for motor drives," IEEE. Trans. on Industrial Electronics, vol. 42, no. 2, April 1995.

[8] H. Zheng, S.-J. Liu, and O. Hu, "Simulation of fuzzy PID control of heave compensation system for deep-ocean mining," Word Journal of Modeling and Simulation. England, vol. 8, no. 1, pp. 50-57, 2012.

[9] P. Pratumsuwan, S. Thongchai, and S. Tansriwong, "A two-Layered fuzzy logic controller for proportional hydraulic system," IEEE.ICIEA, 2009.

[10] A. S. K. Raj, T. M. Kumar, S. S. Mansi, M. P. P. Kumar, and K. S. R. Varum, "Lab view based PID speed control and system identification of a PMDC motor," International Conference on Computing and Control Engineering (ICCCE 2012), vol. 12, no. 13, April, 2011.

[11] G. R. Slemon, "Modeling induction machines for electric drives," IEEE Trans. On Industry Applications, vol. 125, no. 6, pp. 1126-1131, 1989.

[12] R. Krishan, Electrical Motor Drives, Prentrice Hall, 2001.

[13] T. Ahn, Y. Kwon, and H. Kang, "Drive of induction motors using a pseude-on-line Fuzzy-PID controller base on genetic algorithim," Trans. on Control, Automation and System Engineering, vol. 2, no. 2, 2000.

[14] R. Echavarria, S. Hota, and M. Oliver, "A three phase motor drive IGBTs and constant V/F speed control with slip regulation," IV IEEE International Power Electronics Congress Technical Proceedings, pp. 87-91, 1995.

[15] J.-H. Kim, J.-H. Park, S.-W. Lee, and K. P. C. Edwin, "Novel approach to Fuzzy logic controller design for systems with dead zones," ECE Technical Reports, 1992.

[16] A Miloudi, E. A. Al-Radadi, and A. D. Draou, "A variable gain PI controller used for speed control of a direct torque neuro Fuzzy controlled induction machine drive," Turk J Elec Engin, vol. 15, no. 1, 2007.

[17] B. Singh and V. Singhal, "Fuzzy pre-compesated PI control of active filters," Journal of Power Electronics, vol. 8, no. 2, April 2008.

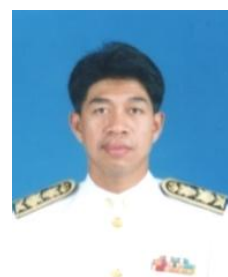

O. Ruksaboon was born in Phetchabun, Thailand, on December 1961. He received the B.S. Tech. Ed., Electrical Technology Power degree from Institute of Technology and Vocational Education Bangkok, Thailand in 1985 and M.S. Tech. Ed., Electrical Technology degree from King's Mongkut University of Technology North Bangkok, Thailand, in 2000.

$\mathrm{He}$ is currently the instructor of the Rajamangala

University of Technology Isan, Khonkaen Campus, Thailand and studying Ph.D., Electrical Education degree in King's Mongkut University of Technology North Bangkok, Thailand. His research interests are power electronics and motor drives. 